\title{
Exploring relationships between Dairy Herd Improvement monitors of performance and the Transition Cow Index in Wisconsin dairy herds
}

\author{
K. K. Schultz, ${ }^{1}$ T. B. Bennett, K. V. Nordlund, D. Döpfer, and N. B. Cook \\ School of Veterinary Medicine, University of Wisconsin, Madison 53706
}

\begin{abstract}
Transition cow management has been tracked via the Transition Cow Index (TCI; AgSource Cooperative Services, Verona, WI) since 2006. Transition Cow Index was developed to measure the difference between actual and predicted milk yield at first test day to evaluate the relative success of the transition period program. This project aimed to assess TCI in relation to all commonly used Dairy Herd Improvement (DHI) metrics available through AgSource Cooperative Services. Regression analysis was used to isolate variables that were relevant to TCI, and then principal components analysis and network analysis were used to determine the relative strength and relatedness among variables. Finally, cluster analysis was used to segregate herds based on similarity of relevant variables. The DHI data were obtained from 2,131 Wisconsin dairy herds with test-day mean $\geq 30$ cows, which were tested $\geq 10$ times throughout the 2014 calendar year. The original list of 940 DHI variables was reduced through expert-driven selection and regression analysis to 23 variables. The K-means cluster analysis produced 5 distinct clusters. Descriptive statistics were calculated for the 23 variables per cluster grouping. Using principal components analysis, cluster analysis, and network analysis, 4 parameters were isolated as most relevant to TCI; these were energy-corrected milk, 3 measures of intramammary infection (dry cow cure rate, linear somatic cell count score in primiparous cows, and new infection rate), peak ratio, and days in milk at peak milk production. These variables together with cow and newborn calf survival measures form a group of metrics that can be used to assist in the evaluation of overall transition period performance.
\end{abstract}

Key words: Dairy Herd Improvement, Transition Cow Index, cluster analysis, principal component analysis, network analysis

Received November 24, 2015.

Accepted May 10, 2016.

${ }^{1}$ Corresponding author: schultz.kelly.k@gmail.com

\section{INTRODUCTION}

Maximizing profitability on a dairy farm is a complex balance of a wide variety of factors, involving business and crop management (McBride and Johnson, 2006), feeding, nutrition, and health management of the cattle. Dairy Herd Improvement metrics can provide producers with powerful information to assist in the management of the operation. Producers can exercise control over many of these parameters, but sometimes at the cost of others. This can be seen in the potential for antagonism between milk yield and fertility (LópezGatius, 2003; Chagas et al., 2007) or between intensification and herd mortality rates (Thomsen and Houe, 2006; Pinedo et al., 2010; Shahid et al., 2015). As a result, success within such a multifactorial environment may be accomplished through multiple strategies, and producers may choose to manage their herds in several successful ways while still achieving adequate overall performance (Brotzman et al., 2015).

The transition period is defined as the 3-wk period before and after parturition (Drackley, 1999; Grummer, 1995), which is a time when the initiation of lactation creates a negative energy balance and leaves the cow susceptible to metabolic disorders, poor future reproductive performance, and infection (Bell, 1995; Drackley, 1999; Esposito et al., 2014; Kay et al., 2015). Effective monitors of the management of this important period are therefore extremely valuable to the dairy producer. Historically, outcomes with significant lag, such as peak milk production or survival, and herd removal rates by 60 DIM (Pinedo et al., 2010; Roberts et al., 2012) have been used. Others have attempted to make use of health outcome records with only modest success due to the variability of disease definition, detection, and recording (Nordlund and Cook, 2004; Moyes et al., 2013; Lukas et al., 2015).

One metric that has been proposed as a measure of early lactation health and performance is the Transition Cow Index (TCI). The TCI was introduced by AgSource Cooperative Services (Verona, WI) in 2006 as a tool to evaluate the transition period at the herd level (Nordlund and Cook, 2004; Nordlund, 2006) and 
was patented though the Wisconsin Alumni Research Foundation (Nordlund et al., 2011). It has been made available in multiple states across the United States, in Quebec, Canada, through a partnership with Valacta (Sainte-Anne-de-Bellevue, Quebec, CA), and is now available in several European countries. In practice, it has become a valuable tool to determine the relative success or failure of management of the transition period. Transition Cow Index is the difference in actual minus predicted milk production at the first DHI test between 4 and 40 DIM expressed on a 305-d basis. The prediction is made for each multiparous cow in the herd based on the previous lactation performance, with the goal of producing an objective measure of fresh cow health and early lactation performance (Nordlund, 2006). Brotzman et al. (2015) conducted cluster analysis (CA) and principal components analysis (PCA) on 557 large dairy herds (>200 cows) in 2011 and found that high TCI was significantly correlated with other predictors that defined high-functioning farms, such as milk production and udder health (Brotzman et al., 2015). However, TCI is not calculated for primiparous cows and is not available for cows that leave the herd early before first DHI milk test. Therefore, it is likely that a combination of metrics is needed to truly represent overall transition performance.

The objective of the current study was to evaluate the associations between TCI in herds of multiple sizes in Wisconsin and a subset of DHI recorded variables that have previously shown to reflect good early lactation performance. This analysis could prove useful in advising producers on use of a package of metrics to assist their understanding of the overall success and failure of the transition period.

\section{MATERIALS AND METHODS}

To meet the aim of evaluating associations between TCI and other DHI variables, a large retrospective data set was required. Data were first obtained from AgSource Cooperative Services and then refined and cleaned to account for missing data or inconsistencies at the farm level, the methods for which are described below. Pearson correlation was used to eliminate variables that were highly redundant in meaning (i.e., all milk weight measures were highly correlated at the herd level) and regression analysis was used to eliminate variables with low impact on the total data variability with regard to TCI. With the resulting data, CA was used to segregate herds into groups based on similarity of multiple characteristics and PCA was used to reduce this subset of variables to those that accounted for the largest amount of variance. These results together al- lowed for visualization of herd similarities and helped focus evaluation toward stronger variable associations. Network analysis was used to determine which variables were most closely related to one another. The composite results of this analysis provided the ability to combine information regarding herd success, TCI, and individual DHI measures.

\section{Creating the Working Data Set}

The DHI monthly test-day records for 3,622 dairy herds, consisting of approximately 647,000 cows in the upper Midwest (Wisconsin, Illinois, Michigan, Minnesota, and Iowa) was provided by AgSource for data collected from January 1 to December 31, 2014. Variables were received from AgSource as 1 of 2 classes, either rolling herd averages (RHA) or direct measurements. The RHA data were collected by retrieving the last recorded date for herd-level values in 2014. Direct measurements were retrieved as the arithmetic mean of the values recorded throughout the study period.

To minimize confounding geographical factors and maximize data reliability, herds were automatically excluded from the study if they were located outside of Wisconsin, if less than 30 animals were in the herd, or if less than 10 monthly test-day records were taken in the study period. Outliers were removed if the herd-average voluntary waiting period until insemination was over $150 \mathrm{~d}$ postpartum or if the herd-average days dry was over $100 \mathrm{~d}$. If the bulk tank deviation (deviation of combined cow test milk weights from actual bulk tank milk weight) was less than $96 \%$ or greater than $110 \%$, values from AgSource were considered inaccurate and associated records were removed from the data set. Predictors with the same entry values in $99 \%$ or more records were removed.

Eighty-eight variables were selected from the original 940 provided by AgSource based on biological relevance to TCI and herd management. These were chosen based on expert knowledge of their use in day-to-day record management and upon theoretical expectations (Balijepally et al., 2011). Four additional variables were created from existing DHI variables. These were peak ratio (ratio of primiparous to multiparous cow peak milk yield), heifer ratio (ratio of number of primiparous cows to number of multiparous cows), mature-equivalent 305-d (ME305) milk yield difference between primiparous cow and second-lactation cows and the ME305 milk yield difference between primiparous cows and all multiparous cows. Data were considered to be missing if not included as a direct measurement or if not included in the last recorded date of RHA data for the year 2014. Zero values were assigned to miss- 
ing values for percentages referring to animal death. These values were cross referenced by comparing them with other AgSource variables that referenced changes in herd population. Predictors with greater than 10\% missing values were deleted from the data set $(\mathrm{n}=3)$ and herds with any remaining missing DHI data points were also deleted $(\mathrm{n}=351)$.

Numeric variables were then entered into a Pearson correlation matrix, checked for linear associations using pairwise scatterplots, and all variables with a greater than 0.9 correlation coefficient were evaluated for exclusion from further analysis (Tremblay et al., 2015). Ultimately, a correlation coefficient of 0.85 was used as a cutoff value for our study. This value captured variables with biological relevance and those that were similar to those reported by Brotzman et al. (2015). When considering highly correlated variables, those that pertained to herd averages were retained over those that pertained to specific lactation groups and variables that pertained to primiparous cows were retained over those that pertained to older groups. All variables were evaluated for normality and log-transformed when skewed upon visual inspection. Herd population was represented as the log-transformation of the average herd cow count for 2014. The final data set of 51 variables described attributes of 2,131 total herds, containing 404,754 total cows in 2014. All data analyses were programmed using the statistical computing software $\mathrm{R}$ (R Core Team, 2015).

\section{Setting Predictors and Elastic Net}

To identify herd variables that were positively or negatively associated with TCI, the data set was submitted to regularized regression via elastic net, which aims to combine the penalties of lasso and ridge regularized regression models (Zou and Hastie 2005). An $\alpha$ parameter was selected to control the number of variables that were selected. This was selected as the best value of 50 iterations over 17 test values of $\alpha$ from 0 to 1 (Zou and Hastie, 2005; Tremblay et al., 2015). Each data set was standardized and submitted to elasticnet regularization using the glmnet package in $\mathrm{R}$ with Gaussian regression methods (Friedman et al., 2010). The model response was the herd-average TCI. The regularization parameter, $\lambda$, was calculated using the cross validation function $\mathrm{cv}$.glmnet. The selected $\alpha$ and $\lambda$ values were applied for elastic net variable selection using the glmnet function.

Variables that were selected by elastic net were submitted to a Gaussian generalized linear model using glm in $\mathrm{R}$ where the model response was herd-average TCI. Further variable selection was done in a backward stepwise regression based on model fit as monitored by the lowest Akaike information criterion statistic (AIC). The number of total variables used was selected at the point where further elimination produced no further decrease in AIC. For this study, final eliminations reduced the data set to 23 variables.

\section{$C A$ and $P C A$}

Prior to CA, variables that were chosen by means of elastic net and Gaussian generalized linear regression analysis were assessed for traits that would confound further interpretation. Three variables were excluded: breed, percent fat, and percent protein. These variables had high association to one another when pertaining to a relatively small number of self-reported nonHolstein-predominant herds, but little variation among self-reported Holstein-predominant herds. Following this assessment, the remainder of this analysis was conducted on herds comprised predominantly of Holstein breed cows $(n=1,983)$.

The remaining variables were all numeric and were scaled to a uniform matrix of mean $=0$ and standard deviation $=1$. A K-means clustering approach was used via the $R$ package vegan to assess the maximum simple structure index of a data set for 2 to 10 potential clusters (Borcard et al., 2011; Oksanen et al., 2015). The final number of clusters used was determined by the optimal simple structure index and the biological relevance of the clusters. A K-means algorithm was used to generate the final clusters (R Core Team, 2015).

Correlations between clusters and the independent variables were assessed by means of PCA (Borcard et al., 2011). Eigenvalues were calculated to express the proportions of variation explained by each principal component level. Significant eigenvalues were determined by the Kaiser-Guttman criterion (Jackson, 1993; Borcard et al., 2011).

Significance between clusters for each variable was determined using a one-way ANOVA and Tukey honestly significant difference test to correct for multiple comparison of means. Statistical significance was declared at an error level $\alpha<0.05$.

\section{Network Analysis}

Networks were obtained using Gaussian chain graph modeling through the minForest function using the gRapHD package in R. In this method, the function provides the optimal network forest and optimal decomposable model with the minimal AIC after 1,000 iterations (Abreu et al., 2010; Højsgaard et al., 2012) 
and returns a visual representation of relatedness between variables.

\section{RESULTS}

\section{$P C A$}

The PCA vector ordination plot is depicted in Figure 1 and the corresponding herd clusters are portrayed in Figure 2. Visualization of the PCA analysis was not affected by inclusion of TCI as a vector, so it was included in Figure 1 for referencing relative vector strengths and directions. The first 8 eigenvalue dimensions were considered relevant by Kaiser-Guttman criterion; however, contrast between clusters disappeared after 5 principal components. Variable contrast was assessed at all relevant PCA dimensions and there was a great deal of redundancy past the second dimension; therefore, discussion of PCA dimensions 1 (21.4\% of variability) and $2(13.0 \%$ of variability) was sufficient for this study.

\section{$C A$}

In the K-means clustering approach, the highest simple structure index (0.009) was sought after while retaining biological interpretability of the number of clusters. This resulted in an optimization at 5 clusters that ranged from 328 to 510 herds composed of Holstein cows only. The resulting 5 clusters were ordered by mean TCI. Clusters 1 to 3 had high mean TCI scores and clusters 4 and 5 had low mean TCI scores. Descriptive statistics for all 5 clusters are presented in Table 1, with the results of the one-way ANOVA and Tukey honestly significant difference analysis included as superscripts.

Generally, herds that exhibited high TCI also exhibited high ECM, better udder health [low somatic cell linear score (test day mean), low new infections (defined as cows $<200 \mathrm{SCC}$ at the prior test, $\geq 200$ at the current test), and high dry cow cure rates (defined as cows $\geq 200$ at the last SCC test of the prior lactation, $<200$ at the first test of the current lactation)], and low peak milk ratio. Similarly, herds that exhibited high TCI usually, but not always, also exhibited longer DIM at peak milk production, lower age at first calving, higher net merit, fewer deaths at less than 60 DIM, and higher rates of calves born alive.

Cluster 1 had the highest average TCI (mean \pm SD; $320.6 \pm 323.7 \mathrm{~kg}$ ). It represented midrange herd sizes $(122.7 \pm 129.2)$ and generally exhibited scores associated with the notion of successful dairy management and production on most significant metrics, including high DIM at peak milk production $(57.7 \pm 4.9 \mathrm{~d})$, earlier age at first calving $(24.9 \pm 1.6 \mathrm{mo})$, highest net merit $(\$ 186.1 \pm 83.5)$, high production in terms of ECM $(36.6 \pm 4.0 \mathrm{~kg})$, low death rates before 60 DIM $(1.6 \pm 1.6 \%)$, low peak ratio $(73.6 \pm 4.0)$, and a small ME305 difference $(132.1 \pm 689.1 \mathrm{~kg})$. Cluster 1 also exhibited better udder health metrics in terms of lowest primiparous cow average linear SCC $(1.9 \pm 0.4)$, high cure rates in dry cows $(71.6 \pm 18.7 \%)$, and low rates of new infection $(15.8 \pm 8.7 \%)$. Cluster 1 did not do poorly in any category (see Table 1 ).

Cluster 5 exhibited the lowest average TCI $(-19.6 \pm$ $354.4 \mathrm{~kg}$ ). This cluster also represented midrange herd sizes $(106.9 \pm 114.7)$. Whereas this cluster had a relatively high DIM at peak milk production $(56.4 \pm 4.9 \mathrm{~d})$, farms in this cluster exhibited generally less favorable scores on most significant metrics, including older age at first calving $(26.4 \pm 2.3 \mathrm{mo})$, low net merit $(\$ 52.9 \pm$ 93.1), low ECM production $(31.8 \pm 4.2 \mathrm{~kg})$, the highest death rates before 60 DIM $(4.8 \pm 2.9 \%)$, lowest rates of calves born alive $(89.5 \pm 6.9 \%)$, high peak ratio $(77.8$ $\pm 5.3)$, and the largest ME305 difference (745.2 \pm 748.9 $\mathrm{kg})$. Cluster 5 exhibited poor udder health metrics in terms of high average primiparous cow linear SCC $(2.5$ $\pm 0.5)$, low dry cow cure rates $(60.5 \pm 17.4 \%)$, and high rates of new infection $(23.3 \pm 10.5 \%)$.

Cluster 3 had the third highest TCI $(255.8 \pm 351.6$ $\mathrm{kg}$ ) and represented the largest herds in Wisconsin $(611.0 \pm 572.6)$. These herds did well in most metrics and had the highest ECM production $(40.8 \pm 3.5 \mathrm{~kg})$, the latest DIM at peak milk production $(61.9 \pm 4.4 \mathrm{~d})$, the earliest age at first calving $(24.0 \pm 1.3 \mathrm{mo})$, high net merit ( $\$ 130.5 \pm 90.4)$, and low peak ratio (74.4 \pm 3.7). Cluster 3 was the only group that generally milked at a frequency higher than twice daily $(3.0 \pm 0.3)$. This cluster also exhibited generally better udder health metrics through low primiparous cow average linear SCC $(2.0 \pm 0.4)$, the lowest rates of new infection (13.3 $\pm 5.0 \%)$, and the highest dry cow cure rates $(75.5 \pm$ $9.4 \%)$. However, cluster 3 exhibited poor performance in a high death rate before 60 DIM $(2.6 \pm 1.5 \%)$ and a high ME305 difference $(688.3 \pm 720.3 \mathrm{~kg})$.

Cluster 2 had high average TCI $(290.4 \pm 316.1 \mathrm{~kg})$ and a low peak ratio $(73.4 \pm 4.2)$. Despite a relatively high TCI, this cluster scored poorly on several metrics. It had the lowest net merit $(\$ 27.2 \pm 73.1)$, midrange ECM production $(34.8 \pm 3.7 \mathrm{~kg})$, mildly poor udder health, and the longest days dry $(65.0 \pm 10.8 \mathrm{~d})$.

Cluster 4 had relatively poor TCI $(8.4 \pm 382.5 \mathrm{~kg})$ and represented the smallest herds $(65.6 \pm 39.5)$, with a wide range of performance in other metrics. Herds in this cluster exhibited the highest calf survival rates $(93.8 \pm 6.8 \%)$ and the lowest death rates before 60 DIM $(1.5 \pm 1.8 \%)$, but also had early DIM at peak milk 


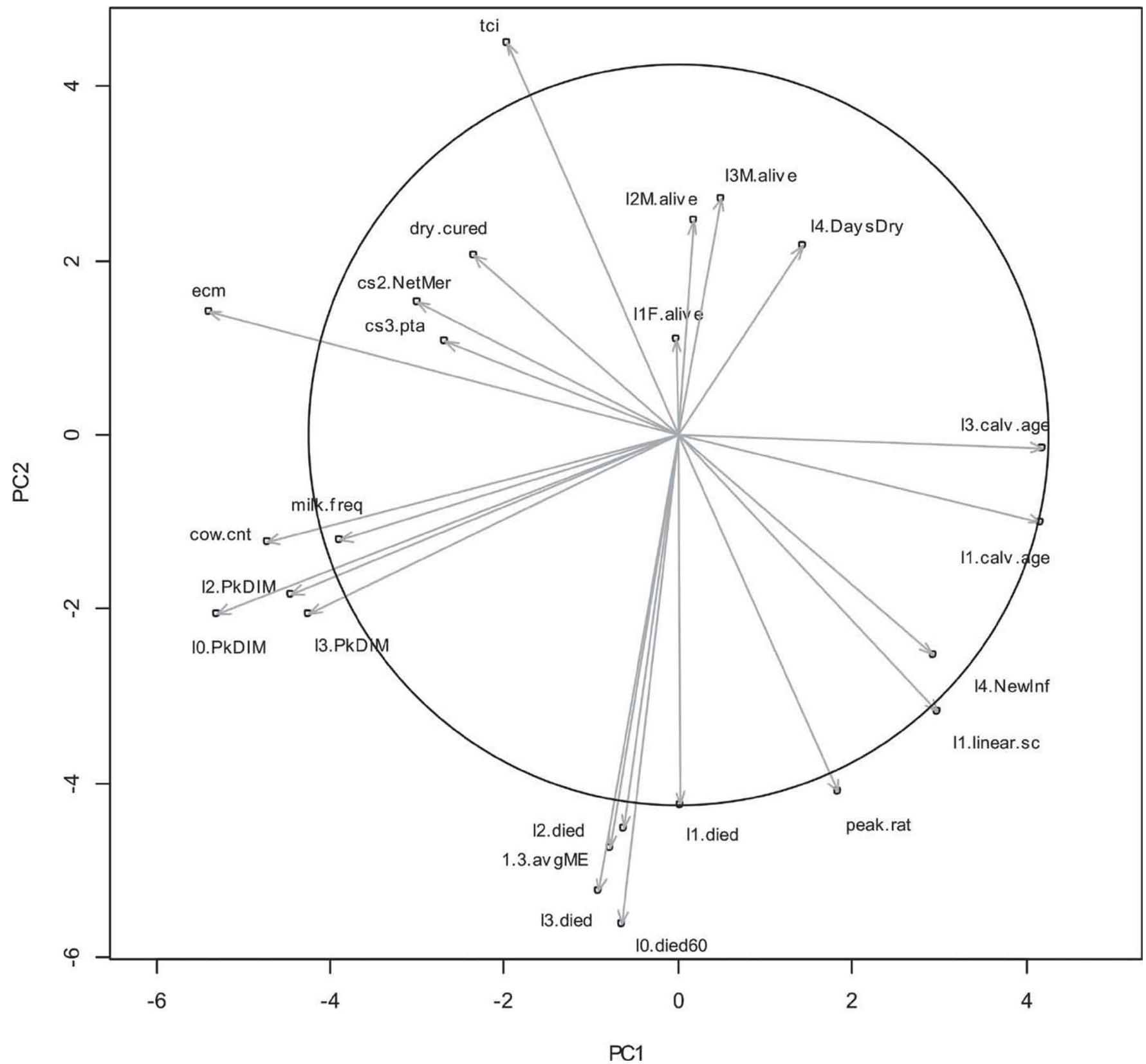

Figure 1. Principal component analysis ordination vectors in the principal component 1 (PC1) and 2 (PC2) planes for variables associated with Transition Cow Index. Vectors that exceed the boundaries of the circle of equilibrium contribution (mean of eigenvalues) are considered meaningful (Borcard et al., 2011). tci = mean Transition Cow Index, standardized; 11F.alive = proportion of female calves born alive to primiparous cows, standardized; $12 \mathrm{M}$.alive $=$ proportion of male calves born alive to second lactation cows, standardized; $13 \mathrm{M}$.alive $=$ proportion of male calves born alive to third-lactation cows, standardized; 14.DaysDry $=$ mean days dry; standardized; breed $=$ predominant breed, standardized as a numeric value; 13 .calv.age $=$ mean age (months) of calving in all cows, standardized; 11.calv.age = mean age (months) of calving in primiparous cows, standardized; fat = rolling herd average $(\mathrm{RHA})$ of percent fat in milk, standardized; pro = RHA of percent protein in milk, standardized; 14.NewInf = proportion of herd with a new IMI (previous test day SCC > 200,000 and current test day SCC >200,000), standardized; 11.linear. $\mathrm{sc}=$ mean linear SCC (log SCC) for primiparous cows, standardized; peak.rat = ratio of mean peak milk kilograms from primiparous cows to mean peak milk kilograms from multiparous cows, standardized; l1.died = proportion of primiparous cows that died before 60 DIM, standardized; 12.died = proportion of second-lactation cows that died before 60 DIM, standardized; 13.died = proportion of third-lactation cows that died before 60 DIM, standardized; 10.died = proportion of all cows that died before 60 DIM, standardized; 1.3.avgME = differential between mature-equivalent 305-d milk yield (ME305) in primiparous cows and third or greater lactation cows, standardized; $12 . \mathrm{PkDIM}=$ mean peak DIM for second-lactation cows, standardized; $13 . \mathrm{PkDIM}=$ mean peak DIM for third or greater lactation cows, standardized; $10 . \mathrm{PkDIM}=$ mean peak DIM for all cows, standardized; cow.cnt $=\log$ of mean adult cow herd size, standardized; milk.freq $=$ mean milking frequency, standardized; ecm $=$ mean ECM, standardized; cs2.ptaProd = mean PTA product for second-lactation cows, standardized; cs3.ptaProd = mean PTA product for third or greater lactation cows, standardized; cs2.NetMer $=$ mean net merit value for second-lactation cows, standardized; dry.cured $=$ proportion of dry period IMI cured (SCC at last test of previous lactation $>200,000$ and SCC at first test of current lactation <200,000), standardized. 
production $(47.7 \pm 5.6 \mathrm{~d})$, the lowest ECM production $(27.7 \pm 4.8 \mathrm{~kg})$, the highest peak ratio $(78.3 \pm 5.6)$, and the oldest age at first calving $(29.3 \pm 3.9 \mathrm{mo})$. This cluster also scored poorly on udder health metrics in terms of the highest primiparous cow average linear SCC $(2.6 \pm 0.5)$, the highest rate of new infections $(25.2 \pm 12.3 \%)$, and the lowest rate of cured dry cows $(58.9 \pm 18.6 \%)$.

\section{Network Analysis}

Network graphing by Gaussian chain graph modeling is depicted in Figure 3. In this model, TCI is centrally located and closely associated with peak ratio and ECM. Relevant factors that relate to calf survival rates at birth and death rates before 60 DIM are linked to TCI. The ME305 difference and days dry were conditionally dependent on peak ratio. All other relevant factors from regression analysis correspond more closely to ECM on the network model.

\section{DISCUSSION}

The purpose of our work was to distill down the key factors involved in evaluating overall early lactation performance. In Brotzman et al. (2015), DHI metrics across herds were analyzed to assess overall parameters of success. Here our aim was to employ similar techniques on the same population to specifically analyze associations between TCI and other metrics available through DHI. Regression analysis, CA, PCA, and network analysis were employed to understand the inherent complexity within DHI data and were successful at providing relevant insight.

The clusters, in and of themselves, were indicative of patterns of dairy management seen in Wisconsin. However, the associations among and between DHI variables with regard to TCI was of equal importance and interest. When assessing the cumulative results of PCA, CA, and network analysis, a few key predictors stood out as recurrently more impactful than the

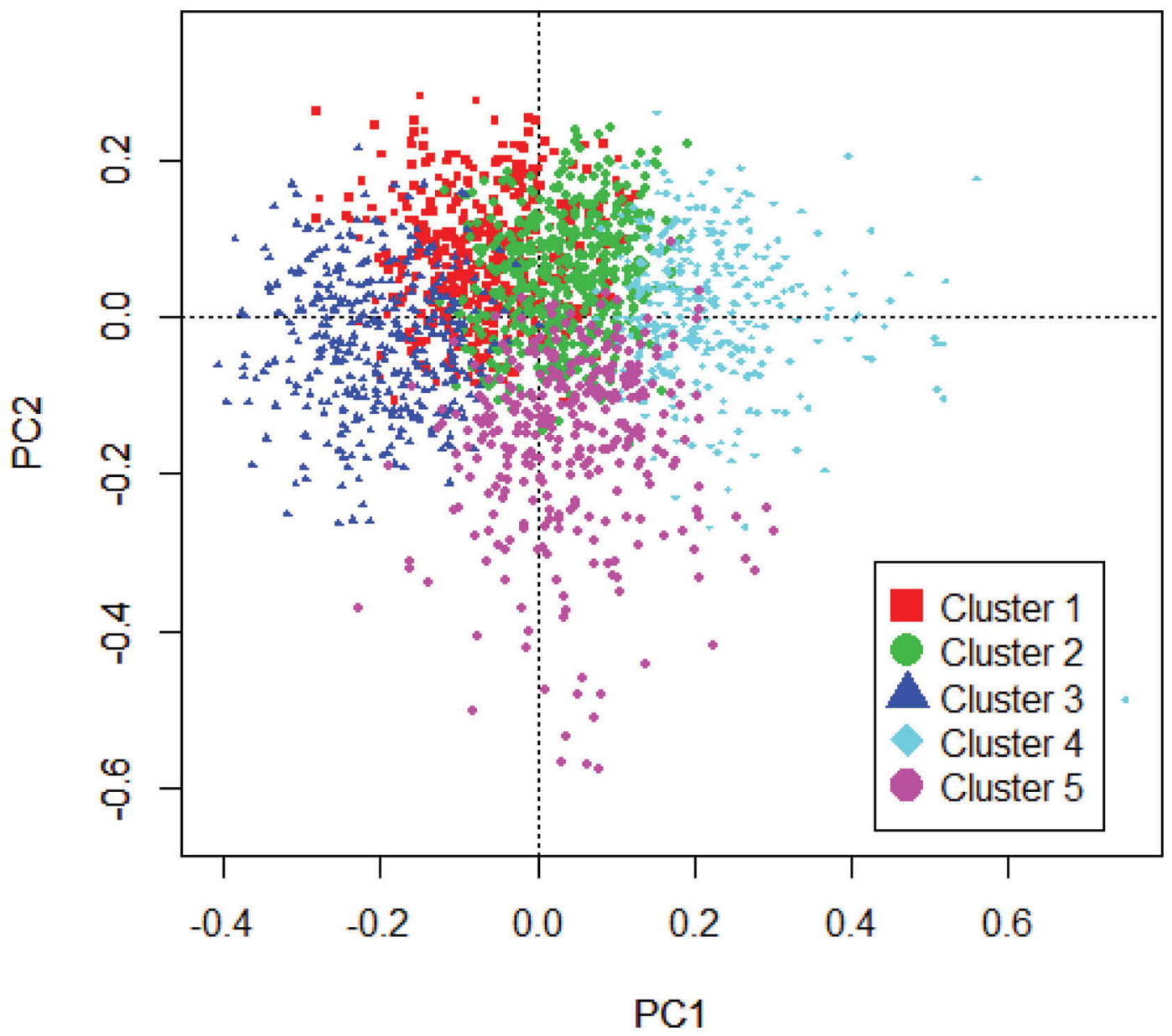

Figure 2. Each herd plotted by principal components analysis ordination at the plane of principal components 1 (PC1) and 2 (PC2) and labeled by cluster. Each cluster is represented by a different shape and color (Borcard et al., 2011). Color version available online. 
Table 1. Herd mean test-day DHI data for 2015 by group for 24 selected variables selected via regression analysis and used in cluster analysis on 1,983 Holstein-predominant Wisconsin dairy herds

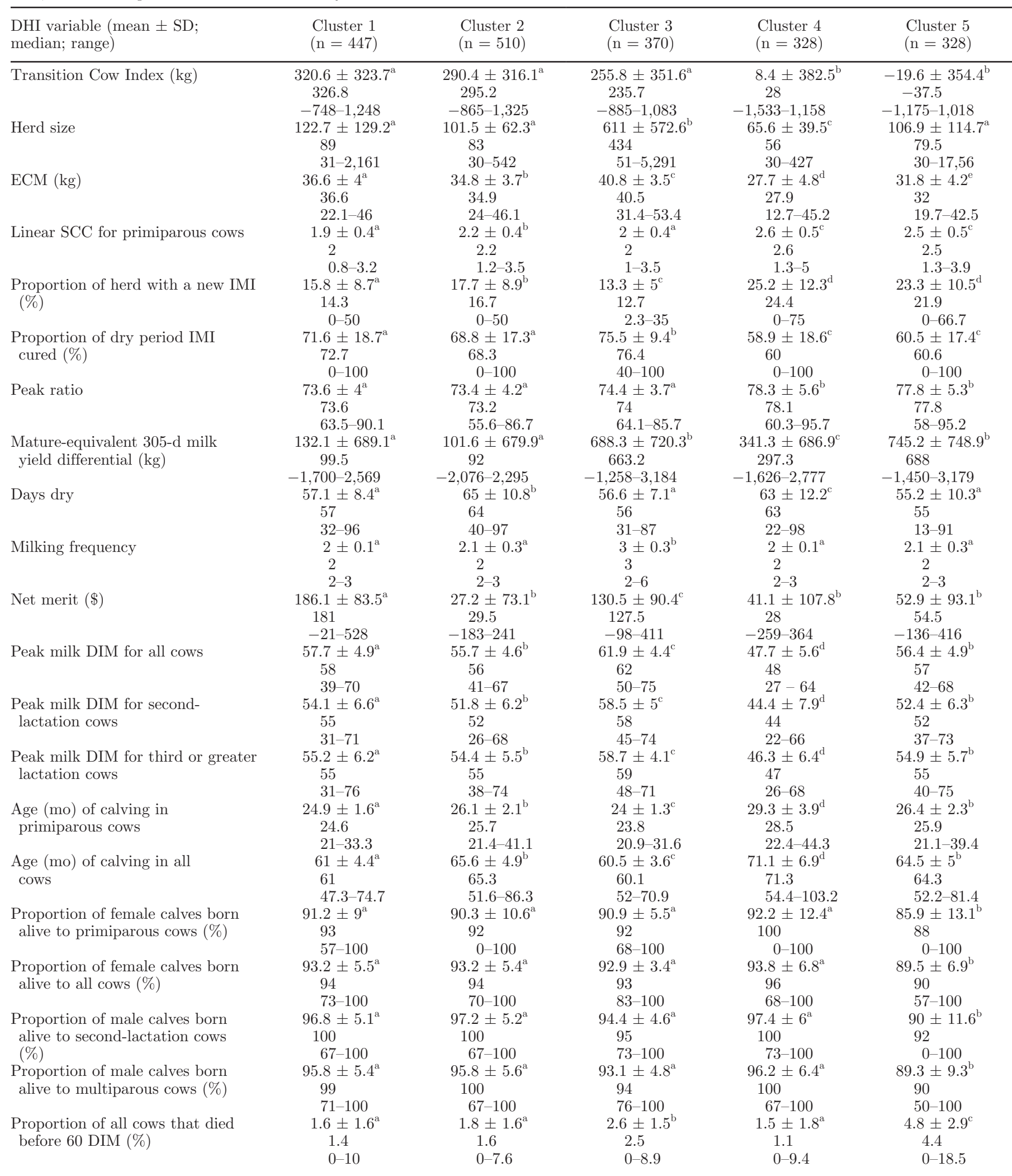


Table 1 (Continued). Herd mean test-day DHI data for 2015 by group for 24 selected variables selected via regression analysis and used in cluster analysis on 1,983 Holstein-predominant Wisconsin dairy herds

\begin{tabular}{|c|c|c|c|c|c|}
\hline $\begin{array}{l}\text { DHI variable (mean } \pm \mathrm{SD} \text {; } \\
\text { median; range) }\end{array}$ & $\begin{array}{l}\text { Cluster } 1 \\
(\mathrm{n}=447)\end{array}$ & $\begin{array}{l}\text { Cluster } 2 \\
(\mathrm{n}=510)\end{array}$ & $\begin{array}{l}\text { Cluster } 3 \\
(\mathrm{n}=370)\end{array}$ & $\begin{array}{l}\text { Cluster } 4 \\
(\mathrm{n}=328)\end{array}$ & $\begin{array}{l}\text { Cluster } 5 \\
(\mathrm{n}=328)\end{array}$ \\
\hline $\begin{array}{l}\text { Proportion of primiparous cows } \\
\text { that died }(\%)\end{array}$ & $\begin{array}{l}2.3 \pm 2.8^{\mathrm{a}} \\
1.6 \\
0-21.4\end{array}$ & $\begin{array}{c}2.5 \pm 3.1^{\mathrm{a}} \\
1.7 \\
0-21.4\end{array}$ & $\begin{array}{c}3.4 \pm 2.2^{\mathrm{b}} \\
3.3 \\
0-11.5\end{array}$ & $\begin{array}{c}2.7 \pm 4.2^{\mathrm{a}} \\
0 \\
0-23.1\end{array}$ & $\begin{array}{c}6.3 \pm 6.3^{\mathrm{c}} \\
5 \\
0-42.9\end{array}$ \\
\hline $\begin{array}{l}\text { Proportion of second-lactation } \\
\text { cows that died }(\%)\end{array}$ & $\begin{array}{l}2.9 \pm 3.8^{\mathrm{a}} \\
0 \\
0-21.9\end{array}$ & $\begin{array}{l}3.3 \pm 4.1^{\mathrm{a}} \\
2.1 \\
0-23.1\end{array}$ & $\begin{array}{l}5.4 \pm 3.2^{\mathrm{b}} \\
\quad 5 \\
0-17.6\end{array}$ & $\begin{array}{c}3.2 \pm 4.8^{\mathrm{a}} \\
0 \\
0-20\end{array}$ & $\begin{array}{l}8 \pm 6.4^{\mathrm{c}} \\
7.3 \\
0-33.3\end{array}$ \\
\hline
\end{tabular}

${ }^{\mathrm{a} e}$ Means within a row with different superscripts differ $(P<0.05)$ based on Tukey honestly significant difference.

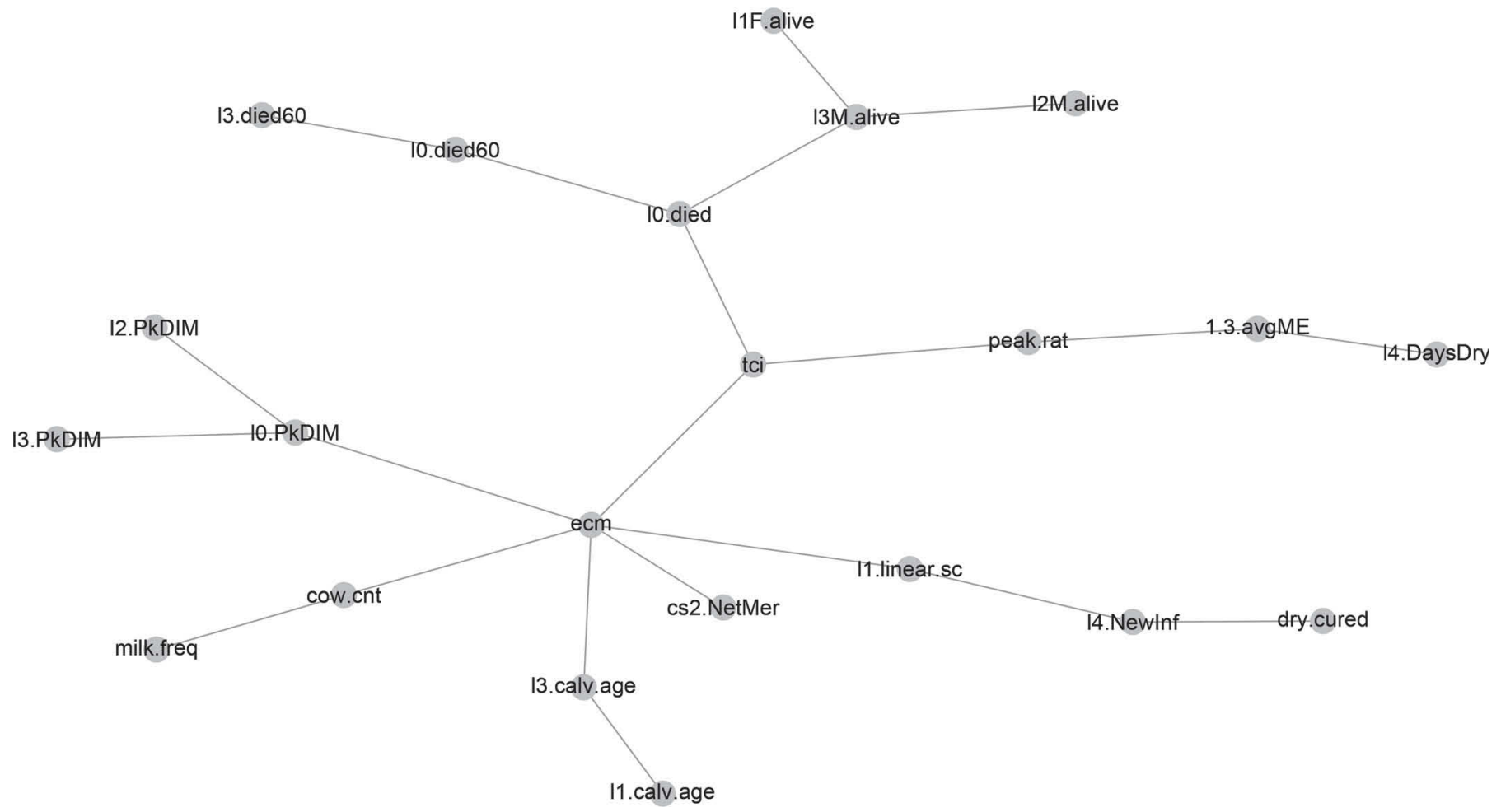

Figure 3. Gaussian chain graph model achieved through a minForest function with 1,000 iterations. This represents an optimal network forest and optimal decomposable model with the minimal achievable Akaike information criterion (Abreu et al., 2010; Højsgaard et al., 2012). tci = mean Transition Cow Index, standardized; l1F.alive $=$ proportion of female calves born alive to primiparous cows, standardized; $12 \mathrm{M}$. alive $=$ proportion of male calves born alive to second-lactation cows, standardized; 13M.alive = proportion of male calves born alive to third-lactation cows, standardized; 14.DaysDry = mean days dry; standardized; breed $=$ predominant breed, standardized as a numeric value; 13. calv.age $=$ mean age (months) of calving in all cows, standardized; 11.calv.age $=$ mean age (months) of calving in primiparous cows, standardized; fat $=$ rolling herd average (RHA) of percent fat in milk, standardized; pro $=$ RHA of percent protein in milk, standardized; 14. NewInf $=$ proportion of herd with a new IMI (previous test day SCC $<200,000$ and current test day SCC $\geq 200,000$ ), standardized; l1.linear.sc $=$ mean linear SCC (log SCC) for primiparous cows, standardized; peak.rat = ratio of mean peak milk kilograms of primiparous cows to mean peak milk kilograms of multiparous cows, standardized; 11.died = proportion of primiparous cows that died before 60 DIM, standardized; 12 .died $=$ proportion of second-lactation cows that died before 60 DIM, standardized; 13.died = proportion of third-lactation cows that died before 60 DIM, standardized; 10.died = proportion of all cows that died before 60 DIM, standardized; 1.3.avgME = differential between mature-equivalent 305-d milk yield (ME305) in primiparous cows and third or greater lactation cows, standardized; $12 . \mathrm{PkDIM}=$ mean peak DIM for second-lactation cows, standardized; 13.PkDIM = mean peak DIM for third or greater lactation cows, standardized; 10.PkDIM = mean peak DIM for all cows, standardized; cow. $\mathrm{cnt}=\log$ of mean adult cow herd size, standardized; milk.freq = mean milking frequency, standardized; ecm = mean ECM, standardized; cs2. ptaProd = mean PTA product for second-lactation cows, standardized; cs3.ptaProd = mean PTA product for third or greater lactation cows, standardized; cs2.NetMer = mean net merit value for second-lactation cows, standardized; dry.cured = proportion of dry period IMI cured (SCC at last test of previous lactation $\geq 200,000$ and SCC at first test of current lactation $<200,000)$, standardized. 
others. These were ECM, 3 measures of udder health (average primiparous cow linear SCC, cure rates in dry cows, and rates of new infection), peak ratio, and DIM at peak milk production (see Figures 1-3).

Energy-corrected milk was the most central predictor within the network analysis and was closely associated with TCI. Energy-corrected milk was closely correlated $(>0.85)$ to all other measures of milk yield and was used as a proxy for them. In the PCA analysis (Figure 1), ECM had high vector strength that ordinated roughly 45 degrees counterclockwise to TCI, indicating a positive but not direct correlation between the 2 factors (Pearson correlation coefficient $=0.54$ ). Clusters 1 to 3 had the highest mean TCI and also had the highest mean ECM and clusters 4 and 5 had low mean ECM. Milk production has been previously shown to be significantly related to metabolic and inflammatory stress associated with the transition period (Chapinal et al., 2012; Huzzey et al., 2015); here it is also shown to relate to TCI.

Three predictors relating to udder health were incorporated into the final analysis, each represented a unique aspect of a herd's ability to deal with IMI: the rate of dry cows curing, the rate of new infections in the herd, and the average linear SCC score of primiparous cows. Within the PCA vector ordination, primiparous cow linear score was the only udder health measure to exceed the mean eigenvalue; however, the rate of new infections was closely associated with it and both were nearly directly opposite in orientation to TCI. The dry cow cure rate also does not exceed the mean eigenvalue, but orients closely to TCI and is directly opposite in orientation from the linear SCC of primiparous cows and the rate of new infections. This directionality is also confirmed in the Pearson correlation matrix. Clusters 1 to 3 , with the highest TCI, also had the best udder health values with low mean linear SCC in primiparous cows, low rates of new infection, and high rates of dry cow cure. Clusters 4 and 5 with low TCI had worse udder health values, represented as high mean primiparous cow linear SCC, high mean rates of new infection, and low mean rates of dry cow cure.

The inflammatory status of the udder during transition was taken into account during the creation of the TCI calculation via the model inclusion of linear SCC score from the previous lactation. The relationship between SCC and udder infection status around dry off and calving has been examined, with Pantoja et al. (2009) demonstrating a significant effect of SCC $>200,000 / \mathrm{mL}$ at both the last and first DHI tests between lactations on first test-day milk. However, we noted that the linear score of primiparous cows, rates of new infection, and the cure rate of dry cows are all key components to the overall picture of fresh cow health and performance in combination with TCI.

Previous studies have linked the transition period to increased systemic inflammatory reactions (Sordillo and Raphael, 2013; Bradford et al., 2015; Huzzey et al., 2015). Acute phase proteins measured via haptoglobin levels are found to peak peripherally during the first week following parturition, even in healthy animals (Humblet et al., 2006; Qu et al., 2014), and increased signs of inflammation can be seen in the liver and adipose tissue during the transition period (Bertoni et al., 2008; Sadri et al., 2010; Gessner et al., 2013).

Peak ratio was also central to the network analysis and was most closely associated with TCI. Peak ratio exceeded the mean eigenvalue within the PCA analysis and oriented almost exactly opposite TCI, which is also observed as a negative correlation within the Pearson correlation matrix. Clusters 1 to 3 with high TCI have low mean peak ratios, and clusters 4 and 5 with low TCI have high mean peak ratios.

Peak ratio is commonly used within DHI record keeping and herd management, but has received little formal attention in the literature. Generally, it is accepted that a peak ratio of $75 \%$ is ideal, as it typically describes the highest-producing herds. Peak ratios that approach $80 \%$ indicate problems in multiparous cows whereas primiparous cows are assumed to be performing relatively better. If values approach $70 \%$ it indicates problems with primiparous cow production relative to well performing multiparous cows (Nordlund and Cook, 2004). Here we see our largest herds performing closest to $75 \%$, as indicated by previous research. Herds that perform better relative to TCI trend below $75 \%$ and herds that perform worse relative to TCI trend above $75 \%$.

Days in milk at peak milk production was closely associated with ECM within the network analysis. Although not central to the network analysis itself, this predictor had one of the highest eigenvalues in PCA, second to ECM. Days in milk at peak milk production was closely associated with herd size and the ordination vector is nearly perpendicular to TCI, which is also evident by a low Pearson correlation coefficient (0.07).

According to standard DHI recommendations, DIM at peak milk production at the herd level is ideal between 55 and 60 DIM (Young, 2002). As a herd-level metric, 55 to 60 DIM is lower than would be intuitive to define peak production (Wasike et al., 2011; López et al., 2015). This is due largely to the inclusion of animals that were culled or died before 100 DIM and to the natural skew toward lower values that is inherent in test-day data. The clusters comprised predominantly by average-sized herds tended to fall within the DHI 
recommended range. Cluster 3 represented the largest herds while having the highest mean value, and cluster 4 represented the smallest herds while having the lowest mean value. This supports the PCA ordination correlation to herd size. The relationship between TCI and herd size as well as DIM at peak milk production appear to be indirectly correlated through other variables.

This work demonstrated the usefulness of various high-powered statistical tools in evaluating a complex, large, multifactorial data set and provides several directions of exploration for consideration in future research relating to herd metrics and TCI. In further work, the network analysis can be pushed to explore causality and could be used to produce models of likelihood to predict herd parameters. Whereas this work does not directly explore causality, it does provide the groundwork to explore these questions.

\section{CONCLUSIONS}

Regression analysis, CA, PCA, and network analysis were used to evaluate DHI variables relating to transition cow health as measured by TCI in dairy herds. Variables were reduced from 940 to 23 and then further prioritized into 4 key management factors. Further, Holstein-predominant herds grouped into 5 clusters. Three of these had high TCI and 2 had low TCI, with various patterns of overall performance inherent in each. The best-performing group in terms of TCI was relatively successful on most metrics and the worst-performing groups had overall less favorable scores. Management factors that were most impactful to TCI were ECM, udder health (linear score of primiparous cows, rate of new infection and the cure rate of dry cows), peak ratio, and DIM at peak milk production. These variables together with measures of cow and newborn calf survival can be used to assist in the evaluation of overall transition period performance.

\section{ACKNOWLEDGMENTS}

The authors appreciate the access to dairy herd data provided by AgSource Cooperative Services (Verona, WI).

\section{REFERENCES}

Abreu, G. C. G., D. Edwards, and R. Labouriau. 2010. High-dimensional graphical model search with the gRapHD R package. J. Stat. Softw. 37:1-18.

Balijepally, V., G. Mangalaraj, and K. Iyengar. 2011. Are we wielding this hammer correctly? A reflective review of the application of cluster analysis in information systems research. J. Assoc. Inf. Syst. 12:375-413.
Bell, A. W. 1995. Regulation of organic nutrient metabolism during transition form late pregnancy to early lactation. J. Anim. Sci. 73:2804-2819.

Bertoni, G., E. Trevisi, X. Han, and M. Bionaz. 2008. Effects of inflammatory conditions on liver activity in puerperium period and consequences for performance in dairy cows. J. Dairy Sci. 91:33003310 .

Borcard, D., F. Gillet, and P. Legendre. 2011. Numerical Ecology with R. Springer. New York, NY.

Bradford, B. J., K. Yuan, J. K. Farney, L. K. Mamedova, and A. J. Carpenter. 2015. Invited review: Inflammation during the transition to lactation: New adventures with an old flame. J. Dairy Sci. 98:6631-6650.

Brotzman, R. L., N. B. Cook, K. Nordlund, T. B. Bennett, A. G. Rivas, and D. Doepfer. 2015. Cluster analysis of Dairy Herd Improvement data to discover trends in performance characteristics in large Upper Midwest dairy herds. J. Dairy Sci. 98:3059-3070.

Chagas, L. M., J. J. Bass, D. Blache, C. R. Burke, J. K. Kay, D. R. Lindsay, M. C. Lucy, G. B. Martin, S. Meier, F. M. Rhodes, J. R. Roche, W. W. Thatcher, and R. Webb. 2007. Invited review: New perspectives on the roles of nutrition and metabolic priorities in the subfertility of high-producing dairy cows. J. Dairy Sci. 90:4022-4032

Chapinal, N., S. J. LeBlanc, M. E. Carson, K. E. Leslie, S. Godden, M. Capel, J. E. P. Santos, M. W. Overton, and T. F. Duffield. 2012. Herd-level association of serum metabolites in the transition period with disease, milk production, and early lactation reproductive performance. J. Dairy Sci. 95:5676-5682.

Drackley, J. K. 1999. Biology of dairy cows during the transition period: The final frontier? J. Dairy Sci. 82:2259-2273.

Esposito, G., P. C. Irons, E. C. Webb, and A. Chapwanya. 2014. Interactions between negative energy balance, metabolic diseases, uterine health and immune response in transition dairy cows. Anim. Reprod. Sci. 144:60-71.

Friedman, J., T. Hastie, and R. Tibshirani. 2010. Regularization paths for generalized linear models via coordinate descent. J. Stat. Softw. $33: 1-22$.

Gessner, D. K., G. Schlegel, J. Keller, F. J. Schwarz, R. Ringseis, and K. Eder. 2013. Expression of target genes of nuclear factor E2related factor 2 in the liver of dairy cows in the transition period and at different stages of lactation. J. Dairy Sci. 96:1038-1043.

Grummer, R. R. 1995. Impact of changes in organic nutrient metabolism on feeding the transition dairy cow. J. Anim. Sci. 73:28202833.

Højsgaard, S., D. Edwards, and S. Lauritzen. 2012. Graphical Models with R. Springer. New York, NY.

Humblet, M. F., H. Guyot, B. Boudry, F. Mbayahi, C. Hanzen, F. Rollin, and J. M. Godeau. 2006. Relationship between haptoglobin, serum amyloid A, and clinical status in a survey of dairy herds during a 6-month period. Vet. Clin. Pathol. 35:188-193.

Huzzey, J. M., S. Mann, D. V. Nydam, R. J. Grant, and T. R. Overton. 2015. Associations of peripartum markers of stress and inflammation with milk yield and reproductive performance in Holstein dairy cows. Prev. Vet. Med. 120:291-297.

Jackson, D. 1993. Stopping rules in principal components-analysisA comparison of heuristic and statistical approaches. Ecology 74:2204-2214.

Kay, J. K., J. J. Loor, A. Heiser, J. McGowan, and J. R. Roche. 2015. Managing the grazing dairy cow through the transition period: A review. Anim. Prod. Sci. 55:936-942.

López, S., J. France, N. E. Odongo, R. A. McBride, E. Kebreab, O. AlZahal, B. W. McBride, and J. Dijkstra. 2015. On the analysis of Canadian Holstein dairy cow lactation curves using standard growth functions. J. Dairy Sci. 98:2701-2712.

López-Gatius, F. 2003. Is fertility declining in dairy cattle? A retrospective study in northeastern Spain. Theriogenology 60:89-99.

Lukas, J. M., J. K. Reneau, R. L. Wallace, and A. De Vries. 2015. A study of methods for evaluating the success of the transition period in early-lactation dairy cows. J. Dairy Sci. 98:250-262. 
McBride, W. D., and J. D. Johnson. 2006. Defining and characterizing approaches to farm management. J. Agric. Appl. Econ. 38:155167 .

Moyes, K. M., T. Larsen, and K. L. Ingvartsen. 2013. Generation of an index for physiological imbalance and its use as a predictor of primary disease in dairy cows during early lactation. J. Dairy Sci. 96:2161-2170.

Nordlund, K. V. 2006. Transition Cow Index. Pages 139-143 in 39th Proc. Am. Assoc. Bovine Practitioners. St. Paul, MN. Frontier Printers, Stillwater, OK.

Nordlund, K. V., T. B. Bennett, G. R. Oetzel, M. K. Clayton, and N. B. Cook. 2011. Method for optimizing health and productivity of milk producing animals. Wisconsin Alumni Research Foundation, assignee. United States patent 7886691.

Nordlund, K. V., and N. B. Cook. 2004. Using herd records to monitor transition cow survival, productivity, and health. Vet. Clin. North Am. Food Anim. Pract. 20:627-649.

Oksanen, J., F. G. Blanchet, R. Kindt, P. Legendre, P. R. Minchin, R. B. O'Hara, G. L. Simpson, P. Solymos, H. H. Stevens, and H. Wagner. 2015. vegan: Community Ecology Package. R package version $2.3-0$.

Pantoja, J. C. F., C. Hulland, and P. L. Ruegg. 2009. Dynamics of somatic cell counts and intramammary infections across the dry period. Prev. Vet. Med. 90:43-54.

Pinedo, P. J., A. De Vries, and D. W. Webb. 2010. Dynamics of culling risk with disposal codes reported by Dairy Herd Improvement dairy herds. J. Dairy Sci. 93:2250-2261.

Qu, Y., A. N. Fadden, M. G. Traber, and G. Bobe. 2014. Potential risk indicators of retained placenta and other diseases in multiparous cows. J. Dairy Sci. 97:4151-4165.

R Core Team. 2015. R: A Language and Environment for Statistical Computing. R Foundation, Vienna, Austria.
Roberts, T., N. Chapinal, S. J. LeBlanc, D. F. Kelton, J. Dubuc, and T. F. Duffield. 2012. Metabolic parameters in transition cows as indicators for early-lactation culling risk. J. Dairy Sci. 95:30573063.

Sadri, H., R. M. Bruckmaier, H. R. Rahmani, G. R. Ghorbani, I. Morel, and H. A. van Dorland. 2010. Gene expression of tumour necrosis factor and insulin signalling-related factors in subcutaneous adipose tissue during the dry period and in early lactation in dairy cows. J. Anim. Physiol. Anim. Nutr. (Berl.) 94:e194-e202.

Shahid, M. Q., J. K. Reneau, H. Chester-Jones, R. C. Chebel, and M. I. Endres. 2015. Cow and herd-level risk factors for on-farm mortality in Midwest US dairy herds. J. Dairy Sci. 98:4401-4413.

Sordillo, L. M., and W. Raphael. 2013. Significance of metabolic stress, lipid mobilization, and inflammation on transition cow disorders. Vet. Clin. N. Am. Food Anim. Pract. 29:267-278.

Thomsen, P. T., and H. Houe. 2006. Dairy cow mortality. A review. Vet. Q. 28:122-129.

Tremblay, M., J. S. Dahm, C. N. Wamae, W. A. De Glanville, E. M. Fèvre, and D. Döpfer. 2015. Shrinking a large dataset to identify variables associated with increased risk of Plasmodium falciparum infection in western Kenya. Epidemiol. Infect. 143:3538-3545.

Wasike, C. B., A. K. Kahi, and K. J. Peters. 2011. Modelling of lactation curves of dairy cows based on monthly test day milk yield records under inconsistent milk recording scenarios. Animal $5: 1780-1790$.

Young, A. 2002. Using Records to Evaluate Production. Electronic publication No. Ag/Dairy - 04. Utah State University Extension Publications. Utah State.

Zou, H., and T. Hastie. 2005. Regularization and variable selection via the elastic net. J. R. Stat. Soc. B. 67:301. 